\title{
Publishing improprieties - a new awakening needed
}

\author{
Om Prakash Yadava ${ }^{1}$ D
}

Published online: 3 November 2020

(C) Indian Association of Cardiovascular-Thoracic Surgeons 2020

Keywords Publishing Frauds $\cdot$ Plagiarism $\cdot$ Peer Review $\cdot$ Ethics $\cdot$ Salami/Duplicate Publication

Pari-Passu with explosion of science, and as a corollary thereof, of scientific and medical publications, there has been an increase in scientific improprieties and fraudsboth quantitative and qualitative. Committee on Publishing Ethics (COPE) guidelines on ethical publication are thwarted, either by design or by default, in myriad ways. Unfortunately, all the focus has been on the authors and sufficient attention has not been paid to the flip side of the coin, that is, the publishers and the editorial office. Statements on ethical compliances are made mandatory for submission of a manuscript from the authors' side, but no similar statement is sought from the handling editors and peer reviewers. Just as the authors can have a conflict of interest, so can the editorial office. It is presumed that the editors and peer reviewers will voluntarily recuse themselves from handling/reviewing a manuscript, when there is a conflict of interest, but no formal and binding statement or certification is mandated from either of them.

The editorial office is generally under pressure, to maintain not only the financial health of the journal, but also the time lines and the quality of scientific contents. Therefore, sometimes, editors solicit articles and at other times are compelled to publish suboptimum articles under duress of deficient submission of manuscripts, albeit to the peril of science. Another off-repeated ploy at subtle coercion is after-hours phone calls from senior authors in influential positions, surreptitiously pressurising and demanding publication. The call is made in the garb of either informing that the paper has been submitted from the unit or seeking some trivial information, or at times even asking for a pre-submission read/review by the Editor on

Om Prakash Yadava

op_yadava@yahoo.com

1 National Heart Institute, New Delhi, India a personal level-all efforts at influencing publication. Matters become worse, if the editor is not senior enough to resist these subtle tactics with malafide intent.

Peer reviewers, more often than not, unwittingly contribute to perpetuating medical frauds related to publications. Most take to reviewership, not for the pride or love of the labour, but for seeking the privileges and the recognition associated with reviewership of journals, to enhance their curriculum vitae. Many reviews are at best cursory with monosyllabic 'Accept' or 'Reject' and a perfunctory, quotidian euphemism-'Good Article', 'Nice Article', 'Novel Article', 'Worth Publication', sans any detailed justification or evidence base provided for its either acceptance or rejection. In part, it is also related to reviewership being an unpaid activity and most surgeons, worth their salt, are always struggling with schedules. It's therefore high time that journals start thinkingshould not peer reviewing be made a paid activity? A suitable, or at least a token, financial compensation should be offered for the reviewers' intellectual indulgence and investment of their time. This will lead to more diligent reviews, which will go a long way not only in improving the quality of science, but also in unearthing of frauds and misdemeanours. Further, going forwards, better quality reviews will act as deterrent to wilful defaulters.

In tandem, indiscretions on part of the authors too in form of blatant plagiarism - both external and self, duplication, salami publication, falsification, obfuscation, and even fabrication of data is rampant and goes on unabashedly. This puts the editorial office under extra work-pressure of putting each article through a duplication/similarity check software (iThenticate). Needless to say, a ferociously wagging tail sans biting teeth is unlikely to make any headway. Punitive and swift action, once any scientific impropriety is detected, therefore becomes an imperative.

The recent initiative by the Indian Association of Thoracic and Cardiovascular Surgery (IACTS) of starting a series of webinars on various aspects of scientific 
publishing, under the 'Editor's choice' series, is indeed a laudable effort. Eyes do not see what the mind does not know. Therefore, before we attempt remedying these maladies facing the profession, we first need to recognise their presence and sensitise the stake holders to their existence. Its only when we succeed in the latter, shall we make any headway addressing them, leave alone eradicating them.

Publisher's note Springer Nature remains neutral with regard to jurisdictional claims in published maps and institutional affiliations. 